\title{
The rapid growth of Australia's advanced age population
}

\section{Tom Wilson*}

Melbourne School of Population and Global Health, The University of Melbourne

* Corresponding author. Email: wilson.t1@ unimelb.edu.au

Jeromey Temple

Melbourne School of Population and Global Health, The University of Melbourne

\begin{abstract}
Australia's population at the highest ages is growing rapidly, driving increasing demand for a whole range of services often required at advanced ages. Unfortunately, official population statistics tend to become less accurate as age increases, especially in the centenarian ages. The aims of the paper are to (i) describe the growth of Australia's population at the highest ages using methods which provide greater accuracy and more detail than is available from official statistical sources; (ii) understand the demographic drivers of population growth at these ages; and (iii) urge caution with the use of official population data at the highest ages, and warn of some of the implications of doing so. State-of-the-art Extinct Generation and Survivor Ratio methods were employed to prepare robust estimates of Australia's population by sex and single years of age for each year of the period 1971 to 2018. Results show that Australia's population at the highest ages is growing very quickly. Over the 20 years to 2018 nonagenarians (those aged 90-99) grew in number from 63,000 to 181,000 (an increase of $185 \%$ ), but centenarians (aged 100+) increased at an even faster rate, growing by $215 \%$ (from about 1,300 to 4,200 ). Official population estimates can be relied upon up to about age 85 , but at higher ages the quality of single year of age population numbers may be poor. We encourage the ABS to adopt the methods described in this paper to produce official population estimates at the highest ages.
\end{abstract}

\section{Keywords}

Australia, centenarians, nonagenarians, oldest old, population estimates 


\section{Introduction}

It is widely appreciated that Australia's population, like that of almost every country in the world, is experiencing population ageing (UN 2017). According to Estimated Resident Population (ERP) data published by the Australian Bureau of Statistics (ABS), the population aged 65 years and above reached 3.91 million in 2018, having increased by 1.64 million or $72 \%$ over the previous 20 years (ABS 2019a). Not only is the 65 and over population growing substantially in numbers (numerical ageing), it is also increasing as a share of the national population (structural ageing), having risen from $12.2 \%$ in 1998 to $15.7 \%$ in 2018. Similarly, the population at the highest ages ( 85 and over) has risen from $1.2 \%$ of the population in 1998 to $2.0 \%$ in 2018 , and is likely to increase to $3.1 \%$ by 2038 (ABS 2018).

Accurate population estimates and projections are essential in assessing demand for a whole range of services often required at the highest ages, including residential aged care, community care, emergency services, and other health services (Gibson and Goss 2019; Mane at al. 2019; Nagaratnam and Nagaratnam 2019). Accurate population numbers are also essential as denominators for important age-specific demographic and social indictors, such as death rates, and dementia and disability incidence. Unfortunately, ERPs and census counts tend to become less accurate as age increases, especially in the centenarian ages (age 100 and above). This problem is not specific to Australia but is common in countries which base their population estimates on census counts (Rosenwaike 1979; Coale and Kisker 1986; Jdanov et al. 2005). Deliberate age inflation by census respondents and census data editing errors have been suggested as causes (Andreev 1999), but it may also be due to inadvertent age misstatement errors. If, at the highest ages, the same proportion of people state their age to be a year older than its true value as state their age to be a year younger, the rapid reduction in population due to mortality results in a greater proportional addition to the older age group; and the outcome is net over-estimation of the population (Preston et al. 1999). However, as we show later, official population estimates at advanced ages have not always been inflated, so other influences may also be contributing to inaccuracy.

This paper presents more accurate population estimates at the highest ages by employing state-of-the-art demographic methods for estimating population at these ages, namely the Extinct Generation and Survivor Ratio methods, which are described in the next section. Demographic research over the last 20 years has proven these types of methods to be highly effective in creating more accurate population numbers of the oldest old than those based on 
the census (Thatcher et al. 2002; Terblanche 2015). A simple Excel/VBA workbook implementing these methods is available from the authors on request. Similar methods are used in the Human Mortality Database (HMD) (www.mortality.org), which includes death rates and population estimates up to very advanced ages for many countries around the world (HMD 2019). Our estimates differ from those in the HMD by being more up-to-date, using deaths input data by single years of age beyond age 100, and are calculated using a recently refined version of the Survivor Ratio method.

The paper has three aims. First, we update and extend population estimates presented earlier (Wilson and Terblanche 2015) because the Australian population at the highest ages is growing quickly. We examine the trends in the nonagenarian and centenarian age groups and determine whether Australia currently has any supercentenarians (aged 110+). Second, we quantify the demographic factors - births, survival, and net migration - responsible for the growth of population in the nonagenarian (aged 90-99) and centenarian age groups over the twenty years to 2018. Third, we urge caution in the use of official population estimates and census counts for advanced age populations and recommend the use of population estimates created from robust methods instead. We present some examples of how the use of lower quality official population data can affect data and analyses, and offer some recommendations about the use of these official data. In addition, following the lead of the UK Office for National Statistics (ONS 2019), we encourage the Australian Bureau of Statistics to adopt the Extinct Generation and Survivor Ratio methods to produce Australia's official population estimates at the highest ages.

\section{Methods}

New population estimates for Australia were prepared by sex and single years of age for ages 85 to 110 at 30th June each year from 1971 to 2018 using the Extinct Generation and Survivor Ratio methods. The Extinct Generation method, as its name suggests, is used to calculate the populations of birth cohorts which have completely died out (Vincent 1951). Calculations are undertaken separately for males and females, and can be applied to all cohorts which have died out by the latest date for which there are deaths data (2018 in this case). The method is simple. Deaths experienced by the cohort at younger ages and earlier years are cumulated one year/age group at a time to obtain single year of age cohort population numbers, and the process continues down to younger ages (age 85 in our application). The method assumes death counts are accurate and complete, and that net 
overseas migration is negligible at the highest ages. These are reasonable assumptions in Australia (Jdanov et al. 2008; Terblanche 2015). Deaths data were obtained from the Australian Bureau of Statistics' ABS.Stat tool (http://stat.data.abs.gov.au/) and customised ABS data orders.

The Extinct Generations method only provides population estimates for cohorts no longer alive. The Survivor Ratio method is used to calculate populations for non-extinct cohorts for the latest date (Dépoid 1973; Thatcher et al. 2002). A Survivor Ratio is defined as the ratio of a cohort's population at age $a$ and time $t$ to its population 5 years earlier when it was 5 years younger:

$R_{a-5, a}(t-5, t)=\frac{P_{a}(t)}{P_{a-5}(t-5)}$

where $R$ denotes the Survivor Ratio, $a$ age group, $a-5$ the age group 5 years younger than age $a, t$ the latest date, $t-55$ years prior to time $t$, and $P$ population. Survivor Ratios, combined with cohort deaths data, permit the populations of non-extinct cohorts to be estimated for the latest date using the equation:

$P_{a}(t)=D_{a-5, a}(t-5, t) \frac{R_{a}}{\left(1-R_{a}\right)}$

where $D$ refers to cohort deaths over the last 5 years and 5 age groups. Population estimates for the latest year are then constrained to sum to the official $85+$ population estimate, an adjustment which has been shown in earlier research to provide the best level of accuracy (Wilson and Terblanche 2018).

Because the calculations occur by cohort back in time, Survivor Ratios are not initially available for the latest year. They are therefore obtained by projecting forwards using linear extrapolation from the previous 20 years of Survivor Ratios. Once population estimates for the latest year have been calculated, cohort deaths can be added at younger ages and earlier years to obtain cohort populations for years prior to the latest date. An iterative sequence of calculations is necessary: the new set of population estimates permit updated Survivor Ratios to be calculated, these are projected out to the latest year again, and then population estimates for the latest year are updated.

To reveal the demographic drivers behind growth in the nonagenarian and centenarian populations we applied Thatcher's decomposition method (Thatcher 1999; Terblanche and Wilson 2014). This divides growth into (i) the effect of growth in the original number of births in the cohort, (ii) the impact of increases in survival over time, and (iii) the growth of 
the populations due to cohort lifetime net overseas migration (calculated as a residual). To distinguish between younger and older age mortality effects, we divided survival into that up to age 65 , and survival above this age. The population of a specified age group may be expressed as the original number of births in that cohort multiplied by survival to the current age range multiplied by a cohort lifetime net overseas migration ratio. If survival is divided into that below and above age 65 then:

$P_{A}^{c}=B^{c} \times \frac{l_{65}^{c}}{l_{0}^{c}} \times \frac{10_{x}^{c}}{\left(10 l_{65}^{c}\right)} \times N^{c}$

where $P_{A}^{c}$ is the population of cohort $c$ currently comprising age group $A, B$ the original number of births in the cohort, $l_{65}^{c} / l_{0}^{c}$ the proportion of the cohort surviving from birth to exact age $65,{ }_{10} L_{x}^{c} /\left(10 l_{65}^{c}\right)$ the survival of the cohort from exact age 65 to a 10 year width age group starting at age $x$, and $N$ is the net overseas migration factor. To decompose the factor increase for an age group between two points in time the ratios of the terms in equation 3 are calculated. For example, the factor increase in the nonagenarian population between two points in time may be expressed as:

$\frac{P_{90-99}^{c 2}}{P_{90-99}^{c 1}}=\frac{B^{c 2}}{B^{c 1}} \times \frac{l_{65}^{c 2} / l_{0}^{c 2}}{l_{65}^{c 1} / l_{0}^{c 1}} \times \frac{10^{L_{90}^{c 2}} /\left(10 l_{65}^{c 2}\right)}{{ }_{10} L_{90}^{c 1} /\left(10 l_{65}^{c 1}\right)} \times \frac{N^{c 2}}{N^{c 1}}$

where $c 1$ and $c 2$ represent the older and younger cohorts respectively. This equation is closely related to the approach of Preston and colleagues for understanding the changing size of specific age groups and the drivers of population ageing (e.g. Preston et al. 2001 p. 173; Preston and Stokes 2012 p. 223).

The data required for decomposition consisted of our new population estimates, births, and cohort life tables. Births by sex were obtained from the ABS (2019b). Deaths and population data to create the life tables were obtained from the Australian Demographic Databank for years prior to 1921, the Human Mortality Database (HMD 2019) for 1921 to 1970, and from 1971 to 2018 ABS deaths and our own newly-created population estimates were used. The accuracy of the decomposition is, of course, dependent on the quality and coverage of historical births and deaths data.

Ethics approval for this project was granted by the Melbourne School of Population and Global Health Human Ethics Advisory Group (Ethics ID 1955518.1). 


\section{Results}

\subsection{Growth of Australia's oldest old population}

Figure 1 illustrates the new estimates of Australia's population at the highest ages from 1971 to 2018. Over the most recent 20 years of this period, Australia's nonagenarian population grew from 63,381 in 1998 to 180,780 in 2018 (an increase of 185\%), while the centenarian population increased from 1,334 to 4,198 (215\%). Our estimates suggest that Australia currently has a very small population of supercentenarians (probably 2), though a few more semi-supercentenarians (those aged 105+). We estimate the semi-supercentenarian population to have grown from 69 in 1998 to 202 in 2018 (an increase of 194\%). By way of comparison, Australia's total population increased by 34\% between 1998 and 2018 (ABS 2019a). Given the higher mortality of males relative to females at all ages it is not surprising to find that females constitute the majority of nonagenarians (67\% in 2018), centenarians (81\%), and semi-supercentenarians $(87 \%)$.

The dashed lines in Figure 1 show ABS ERPs for nonagenarians and centenarians (ERPs are not published for semi-supercentenarians). The alignment of the new nonagenarian estimates with ERPs is close, but the difference between the two centenarian population datasets is striking, especially in the years around the turn of the 21 st century. The centenarian ERP for males has nearly always been too high, while the female ERP has fluctuated either side of our estimates. Although population numbers are small, the large fluctuations over time seem implausible given the absence of commensurate swings in births, migration, and mortality.

Table 1 presents the new estimates of Australia's population at the highest ages by sex and single years of age in 2018 and for 20 years earlier, together with equivalent ERPs for comparison. ERPs from age 85 to the low 90s are generally in close agreement with our estimates, all being within $10 \%$ up to age 93. The discrepancy is far worse in 1998 than 2018, and at higher ages there are generally larger proportional discrepancies, especially for males. This is consistent with Preston et al.'s (1999) argument mentioned earlier about the bias resulting from age misstatement in the census. The effect is greater where population numbers tail off rapidly due to mortality - a phenomenon which occurs to a greater extent for males than females. Table A in the Appendix similarly compares our estimates in 2016 with 2016 Census counts and 2016 ERPs. 

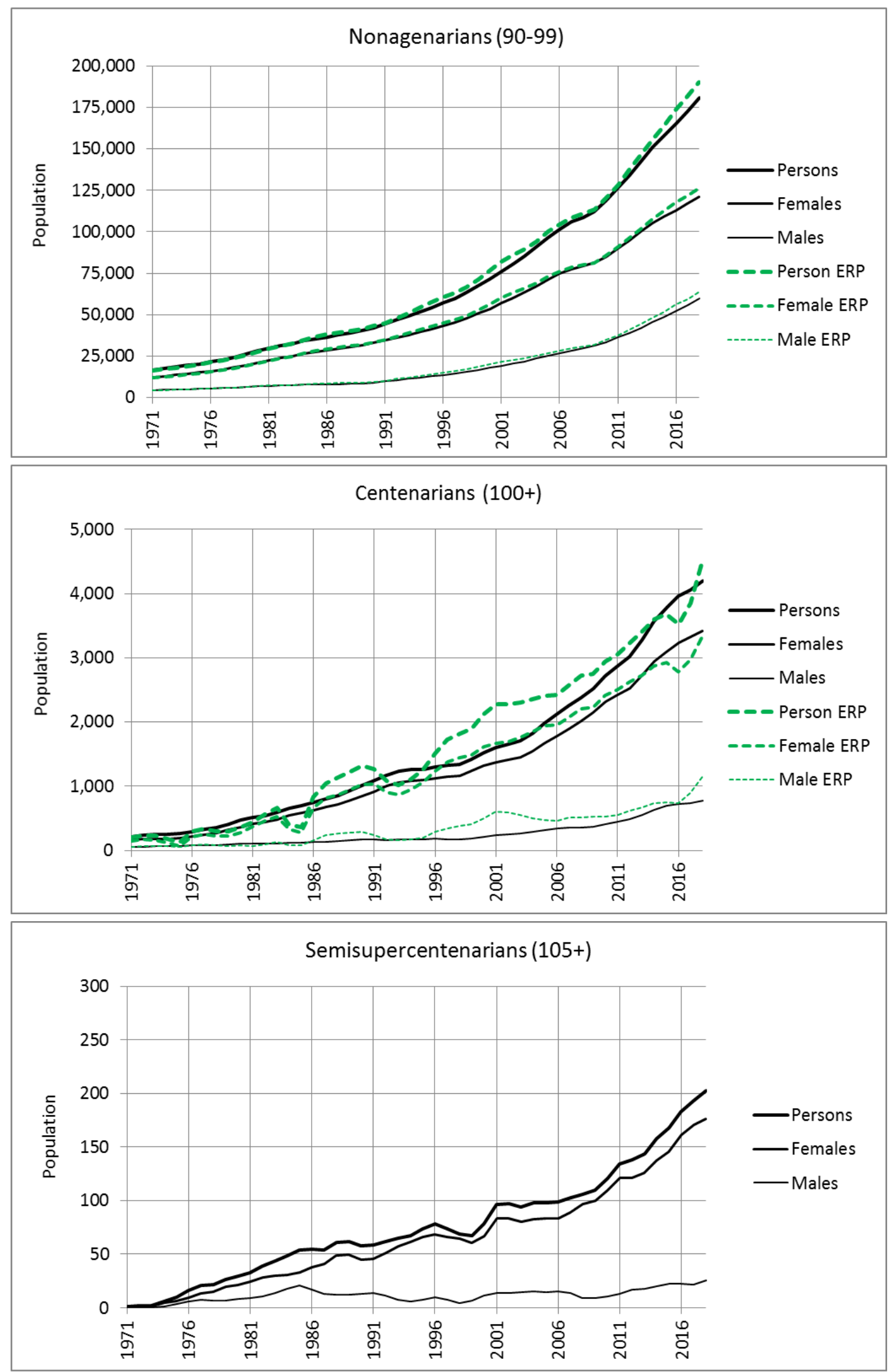

Figure 1: Australia's population at the highest ages, 1971-2018

Source: the authors; ABS 
Table 1: Australia's population at the highest ages, 1998 and 2018

\begin{tabular}{|c|c|c|c|c|c|c|c|c|}
\hline \multirow[b]{3}{*}{ Age } & \multicolumn{4}{|c|}{ New estimates } & \multicolumn{4}{|c|}{ ABS ERPs } \\
\hline & \multicolumn{2}{|c|}{1998} & \multicolumn{2}{|c|}{2018} & \multicolumn{2}{|c|}{1998} & \multicolumn{2}{|c|}{2018} \\
\hline & Males & Females & Males & Females & Males & Females & Males & Females \\
\hline 85 & 14,227 & 27,706 & 33,216 & 43,896 & 14,541 & 27,565 & 31,155 & 42,275 \\
\hline 86 & 11,616 & 23,913 & 29,621 & 40,909 & 11,976 & 24,426 & 28,135 & 39,086 \\
\hline 87 & 9,396 & 20,553 & 26,283 & 38,130 & 9,731 & 20,893 & 25,619 & 37,589 \\
\hline 88 & 7,566 & 17,415 & 22,681 & 34,577 & 7,956 & 18,011 & 22,738 & 34,220 \\
\hline 89 & 5,930 & 14,514 & 19,017 & 30,363 & 6,077 & 14,209 & 18,592 & 29,646 \\
\hline 90 & 4,521 & 11,924 & 15,621 & 26,222 & 4,714 & 11,815 & 15,854 & 26,497 \\
\hline 91 & 3,393 & 9,563 & 12,466 & 22,303 & 3,551 & 9,601 & 12,637 & 22,823 \\
\hline 92 & 2,518 & 7,478 & 9,647 & 18,667 & 2,705 & 7,621 & 10,342 & 19,530 \\
\hline 93 & 1,799 & 5,707 & 7,240 & 15,291 & 1,921 & 5,897 & 7,672 & 15,917 \\
\hline 94 & 1,224 & 4,254 & 5,232 & 12,135 & 1,394 & 4,535 & 5,828 & 12,661 \\
\hline 95 & 834 & 3,129 & 3,688 & 9,338 & 1,043 & 3,411 & 4,131 & 9,802 \\
\hline 96 & 567 & 2,264 & 2,532 & 6,945 & 745 & 2,541 & 3,071 & 7,514 \\
\hline 97 & 369 & 1,617 & 1,654 & 4,910 & 539 & 1,857 & 2,160 & 5,740 \\
\hline 98 & 221 & 1,130 & 1,004 & 3,243 & 388 & 1,317 & 1,435 & 3,772 \\
\hline 99 & 121 & 748 & 585 & 2,058 & 190 & 779 & 741 & 1,985 \\
\hline 100 & 74 & 467 & 345 & 1,343 & $\mathrm{n} / \mathrm{a}$ & $\mathrm{n} / \mathrm{a}$ & $\mathrm{n} / \mathrm{a}$ & $\mathrm{n} / \mathrm{a}$ \\
\hline 101 & 46 & 290 & 201 & 874 & $\mathrm{n} / \mathrm{a}$ & $\mathrm{n} / \mathrm{a}$ & $\mathrm{n} / \mathrm{a}$ & $\mathrm{n} / \mathrm{a}$ \\
\hline 102 & 24 & 181 & 114 & 535 & $\mathrm{n} / \mathrm{a}$ & $\mathrm{n} / \mathrm{a}$ & $\mathrm{n} / \mathrm{a}$ & $\mathrm{n} / \mathrm{a}$ \\
\hline 103 & 14 & 104 & 62 & 314 & $\mathrm{n} / \mathrm{a}$ & $\mathrm{n} / \mathrm{a}$ & $\mathrm{n} / \mathrm{a}$ & $\mathrm{n} / \mathrm{a}$ \\
\hline 104 & 7 & 59 & 31 & 177 & $\mathrm{n} / \mathrm{a}$ & $\mathrm{n} / \mathrm{a}$ & $\mathrm{n} / \mathrm{a}$ & $\mathrm{n} / \mathrm{a}$ \\
\hline 105 & 3 & 33 & 15 & 92 & $\mathrm{n} / \mathrm{a}$ & $\mathrm{n} / \mathrm{a}$ & $\mathrm{n} / \mathrm{a}$ & $\mathrm{n} / \mathrm{a}$ \\
\hline 106 & 2 & 15 & 7 & 46 & $\mathrm{n} / \mathrm{a}$ & $\mathrm{n} / \mathrm{a}$ & $\mathrm{n} / \mathrm{a}$ & $\mathrm{n} / \mathrm{a}$ \\
\hline 107 & 0 & 8 & 3 & 22 & $\mathrm{n} / \mathrm{a}$ & $\mathrm{n} / \mathrm{a}$ & $\mathrm{n} / \mathrm{a}$ & $\mathrm{n} / \mathrm{a}$ \\
\hline 108 & 0 & 5 & 1 & 10 & $\mathrm{n} / \mathrm{a}$ & $\mathrm{n} / \mathrm{a}$ & $\mathrm{n} / \mathrm{a}$ & $\mathrm{n} / \mathrm{a}$ \\
\hline 109 & 0 & 3 & 0 & 4 & $\mathrm{n} / \mathrm{a}$ & $\mathrm{n} / \mathrm{a}$ & $\mathrm{n} / \mathrm{a}$ & $\mathrm{n} / \mathrm{a}$ \\
\hline $110+$ & 0 & 2 & 0 & 2 & $\mathrm{n} / \mathrm{a}$ & $\mathrm{n} / \mathrm{a}$ & $\mathrm{n} / \mathrm{a}$ & $\mathrm{n} / \mathrm{a}$ \\
\hline 90-99 & 15,567 & 47,814 & 59,669 & 121,111 & 17,190 & 49,374 & 63,871 & 126,241 \\
\hline $100+$ & 169 & 1,165 & 779 & 3,419 & 378 & 1,445 & 1,155 & 3,348 \\
\hline
\end{tabular}

Source: Authors' calculations; ABS

\subsection{Drivers of nonagenarian and centenarian population growth}

What demographic drivers lie behind the rapid growth of Australia's population at the highest ages? The growth of the nonagenarian population between 1998 and 2018 was due to increases in births, improvements in survival, and greater net migration gains. Using the decomposition of growth set out in equation 4, Table 2 reveals the magnitude of each the 
growth factors: the largest contributor to growth was improvements in survival above age 65, with more moderate contributions due to increases in births, improvements in survival from birth to age 65, and a very modest contribution from net overseas migration (rounded down to 1.0). Greater improvements in survival among older ages occurred for males. The product of these component factors is the total factor growth of the population over the 1998-2018 period (e.g. the male population of nonagenarians in 2018 was 3.8 times its size in 1998). The explanation for the growth in centenarian numbers over the same period is similar although net overseas migration made a slightly larger contribution.

Table 2: Drivers of population increase between 1998 and 2018 for nonagenarians and centenarians

\begin{tabular}{lrrrrrr}
\hline & \multicolumn{3}{c}{ Nonagenarians } & \multicolumn{3}{c}{ Centenarians } \\
Factor & Males & Females & Persons & Males & Females & Persons \\
\hline Births & 1.3 & 1.3 & 1.3 & 1.2 & 1.2 & 1.2 \\
Survival to age 65 & 1.2 & 1.2 & 1.2 & 1.1 & 1.2 & 1.1 \\
Survival from 65 to age group & 2.5 & 1.7 & 1.9 & 2.4 & 1.9 & 2.0 \\
Net overseas migration & 1.0 & 1.0 & 1.0 & 1.4 & 1.1 & 1.2 \\
\hline Total factor increase & 3.8 & 2.5 & 2.9 & 4.6 & 2.9 & 3.1 \\
\hline
\end{tabular}

Source: authors' calculations using equation 4.

Note that the four factors (births, survival to age 65 , survival from age 65 , and net overseas migration) are multiplied together to obtain the total factor increase.

\subsection{Improved population measurement and mortality sensitivity}

Accurate estimates of populations at the highest ages are critical from measurement of a range of demographic events. As a simple evaluation exercise, it is useful to consider whether updates to other indices are reasonable. For example, consider age-specific death rates which form key inputs to life tables and mortality projections (and thus population projections). Figure 2 shows age-specific death rates at the highest ages for 1996-98 and 2016-18 over ages 80-104 and 105+ calculated using the new estimates in the denominator alongside those based on ERPs. Although the rates in the centenarian ages are quite noisy due to small numbers of deaths, the fundamental pattern of increasing rates with increasing age is evident. In 1996-98, ERP-based rates in the high ages diverge from rates based on the new estimates around age 93 for males and about age 95 for females. In addition, the ERP-based rates show an apparent mortality crossover at about age 97 when male death rates drop below female rates. In the more recent period female ERP-based rates follow those based on new population estimates closely, but those for males are still too low in the high 90s. 

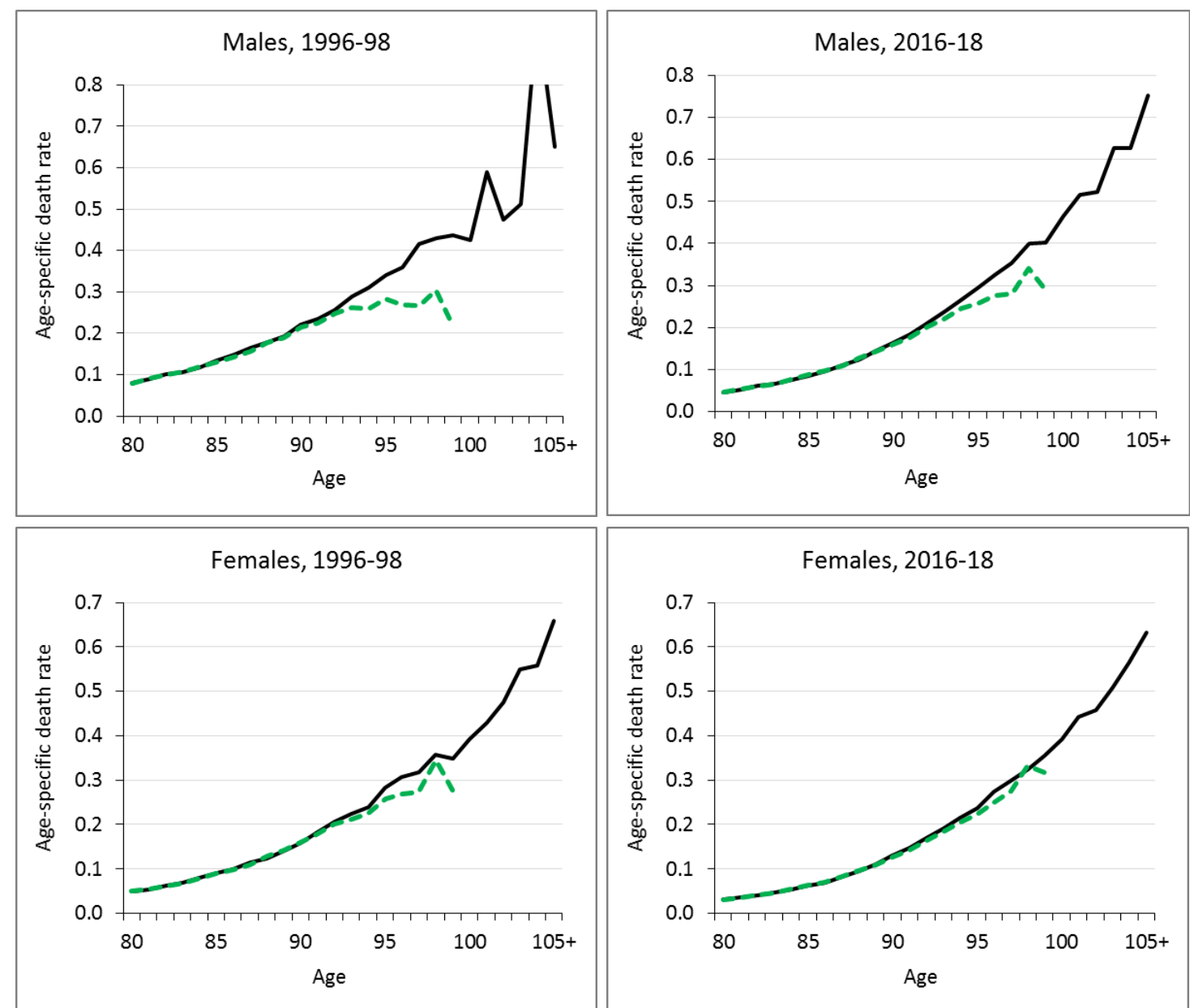

Rates based on new estimates

- - Rates based on ERPs

Figure 2: Age-specific death rates, ages 85-105+, 1996-98 and 2016-18

Source: the authors; ABS

\section{Discussion}

This paper has presented up-to-date estimates of Australia's population at the highest ages using methods proven to provide more accurate numbers. Population increase in the nonagenarian age group has been rapid over the 1971-2018 period, though the centenarian population has grown at an even faster rate. With increasing numbers of births and improved survival in the older adult age groups, high growth in oldest old populations can be expected to continue in coming decades.

Good quality population estimates at high ages result in more accurate assessments of demand for services required at advanced ages, as well as more reliable demographic and socioeconomic rates and indicators for which they provide the denominator. ABS census counts and ERPs at advanced ages are widely used by researchers and practitioners and, quite understandably, are assumed to be reliable. Unfortunately, this is not always the case. 
Use of official population data at advanced ages may lead to inaccuracies; some of these will be immaterial, but others may affect measurements and analyses. For example, estimates of populations at advanced ages and their growth over time can be misleading. For example, a recent paper states that the nonagenarian population had been the fastest growing age group of the Australian population over the 2006-16 period (Gibson and Goss 2019). This is the correct interpretation of official population data, but more accurate population estimates indicate that centenarians were actually the fastest growing age group over the decade (increasing by $87 \%$ between 2006 and 2016 compared to $62 \%$ for nonagenarians). A further example is the measurement issues arising due the use of population estimates as denominators in mortality estimates. Our analyses underscores the fact that the differences between the two sets of agespecific death rates (one using the ABS ERP counts and a second using our updated estimates) are substantial for some advanced age groups and will result in noticeably different outcomes in life tables and projections of advanced age populations.

Given the high rate of growth of these age groups, accurate and regularly updated population estimates are important for planning, policy formulation, and research related to advanced age populations including, but not limited to, residential aged care, community care, emergency and other health services. Although populations in the highest age groups are relatively low, numbers are projected to increase significantly over time and the health and care services utilised at these ages can be very costly to Governments. Recent research from several countries point to the growing demand for health services by octogenarians, nonagenarians and centenarians over recent years and the need to tailor services and treatment regimes to this growing group (e.g. Bradao et al. 2017; Matsuyama et al. 2017). Accurate population counts are critical to this endeavour.

Our study contains a number of limitations, of course. The alternative population estimates presented in the paper are dependent on accurate and complete deaths data, a reliable official ERP for the 85+ age group, and negligible net overseas migration at the highest ages. None of these data sources and assumptions are perfect. The quality of deaths data has been judged as reasonable since the 1970s, although less good prior to that (Jdanov et al. 2008; Terblanche 2015). The decomposition is additionally dependent on reliable historical births data, and these data may also be subject to some degree of under-coverage, particularly amongst the Aboriginal and Torres Strait Islander population. 
We encourage the Australian Bureau of Statistics to produce official population estimates at the highest ages using the Extinct Generation and Survivor Ratio methods. The methods are relatively simple, require only modest amounts of input data, and are therefore easy and inexpensive to implement. In addition, opportunities exist for comparing census and Post Enumeration Survey (PES) data with administrative data collections to cross-check population estimates at the highest ages. For example, data collected as part of the Aged Care Assessment Program, Aged Care Funding Instrument, Medicare Benefits Schedule, and Pharmaceutical Benefits Scheme, are all worth exploring.

When using currently available ERPs we would advise against placing too much reliance on numbers in the nonagenarian and centenarian ages, and recommend ERPs be used for ages 0, $1,2, \ldots$, up to 84 with a final open-ended age group of $85+$. Researchers and practitioners seeking more reliable single year of age population data at higher ages can download an Excel file of alternative population estimates from the Centre of Excellence in Population Ageing Research website at www.cepar.edu.au, or obtain it on request from the corresponding author of the paper.

\section{Funding}

This work was funded by the Australian Research Council's (ARC) Centre of Excellence in Population Ageing Research (CE1101029).

\section{References}

Andreev, K. F. (1999). Demographic Surfaces: Estimation, Assessment and Presentation, with Application to Danish Mortality, 1835-1995. PhD thesis. Odense: University of Southern Denmark.

https://www.demogr.mpg.de/en/projects_publications/publications_1904/dissertations/d emographic_surfaces_estimation_assessment_and_presentation_with_application_to_da nish_mortality_148.htm

Australian Bureau of Statistics (ABS) (2018). Population Projections, Australia, 2017 (base) - 2066. Catalogue No. 3222.0. Canberra: ABS.

Australian Bureau of Statistics (ABS) (2019a). Australian Demographic Statistics, Mar 2019. Catalogue No. 3101.0. Canberra: ABS.

Australian Bureau of Statistics (ABS) (2019b). Australian Historical Population Statistics, 2016. Catalogue No. 3105.0.65.001. Canberra: ABS. 
Bradao, D., Ribeiro, O., Freitas, A., \& Paul, C. (2017). Hospital admissions by the oldest old: Past trends in one of the most ageing countries in the world. Geriatrics and Gerontology International, 17(11), 2255-2265.

Coale, A. J., \& Kisker, E. E. (1986). Mortality crossovers: reality or bad data? Population Studies, 40(3), 389-401.

Dépoid, F. (1973). La mortalité des grands vieillards. Population (French Edition), 28(4/5), 755-792.

Gibson, D., \& Goss, J. (2019). Ninety and not out - understanding our oldest old. Australasian Journal on Ageing, https://doi.org/10.1111/ajag.12695

Jdanov, D. A., Jasilionis, D., Soroko, E. L., Rau, R., \& Vaupel, J. W. (2008). Beyond the Kannisto-Thatcher Database on Old Age Mortality: an assessment of data quality at advanced Ages. MPIDR Working Paper WP 2008-013. https://www.demogr.mpg.de/papers/working/wp-2008-013.pdf.

Jdanov, D. A., Scholz, R. D., \& Shkolnikov, V, M. (2005). Official population statistics and the Human Mortality Database estimates of populations aged 80+ in Germany and nine other European countries. Demographic Research, 13(14), 335-362.

Mane, G., Alkhouri, H., Dinh, M., \& McCarthy, S. (2019). One hundred and counting: centenarian use of emergency departments in New South Wales. Emergency Medicine Australasia, 31(4), 626-631.

Matsuyama, T., Kitamura, T., Katayama, Y., Kiyohara, K., Hayashida, S., Kawamura, T., Iwami, T., \& Ohta, B. (2017). Factors associated with the difficulty in hospital acceptance among elderly emergency patients: A population-based study in Osaka City, Japan. Geriatrics and Gerontology International, 17(12), 2441-2448.

Nagaratnam, K. \& Nagaratnam, N. (2019). Long-term care, nursing homes and support services. In Nagaratnam, N., Nagaratnam, K., \& Cheuk, G. (eds.), Advanced Age Geriatric Care (pp. 39-43). Cham: Springer.

Office for National Statistics (ONS) (2019). Estimates of the very old, including centenarians, QMI. London: ONS.

Preston, S. H., Elo, I. T., \& Stewart, Q. (1999). Effects of age misreporting on mortality estimates at older ages. Population Studies, 53(2), 165-177.

Preston, S. H., Heuveline, P., \& Guillot, M. (2001). Demography: Measuring and Modeling Population Processes. Malden MA: Blackwell.

Preston, S. H., \& Stokes, A. (2012). Sources of population aging in more and less developed countries. Population and Development Review, 38(2), 221-236. 
Rosenwaike, I. (1979). A new evaluation of United States census data on the extreme aged. Demography, 16(2), 279-288.

Terblanche, W. (2015). Population Estimates and Projections for Australia's Very Elderly Population at State and National Level. PhD thesis. Brisbane: The University of Queensland; 2015. https://espace.library.uq.edu.au/view/UQ:371462.

Terblanche, W. \& Wilson, T. (2014). Understanding the growth of Australia's very elderly population, 1976-2012. Journal of Population Ageing, 7(4), 301-322.

Terblanche, W. \& Wilson, T. (2015). An evaluation of nearly-extinct cohort methods for estimating the very elderly populations of Australia and New Zealand. PLOS ONE, 10(4), e0123692.

Thatcher, A. R. (1999). The demography of centenarians in England and Wales. Population Trends, 96 (Summer 1999), 5-12.

Thatcher, R., Kannisto, V., \& Andreev, K. (2002). The Survivor Ratio method for estimating numbers at high ages. Demographic Research, 6(1), 1-18.

The Human Mortality Database (HMD) (2019). University of California, Berkeley (USA), and Max Planck Institute for Demographic Research (Germany). https://www.mortality.org/.

United Nations Population Division (2017). World Population Ageing 2017. New York: United Nations.

Vincent, P. (1951). La mortalité des vieillards. Population (French Edition), 6(2), 181-204.

Wilson, T., \& Terblanche, W. (2018). New estimates of Australia's centenarian population International Journal of Population Data Science, 3(1), 1-10. 


\section{Appendix}

Table A: Australia's population at the highest ages, 2016

\begin{tabular}{|c|c|c|c|c|c|c|}
\hline \multirow[b]{2}{*}{ Age } & \multicolumn{2}{|c|}{ New estimates } & \multicolumn{2}{|l|}{ ABS ERPs } & \multicolumn{2}{|c|}{2016 Census counts } \\
\hline & Males & Females & Males & Females & Males & Females \\
\hline 85 & 31,895 & 43,889 & 31,394 & 43,526 & 31,758 & 44,345 \\
\hline 86 & 28,279 & 40,707 & 28,344 & 40,422 & 28,756 & 41,222 \\
\hline 87 & 24,482 & 36,716 & 24,168 & 36,217 & 24,297 & 36,631 \\
\hline 88 & 20,889 & 32,763 & 21,115 & 33,226 & 21,256 & 33,519 \\
\hline 89 & 17,308 & 28,910 & 17,423 & 29,574 & 17,427 & 29,745 \\
\hline 90 & 14,000 & 25,133 & 14,635 & 26,058 & 14,676 & 26,157 \\
\hline 91 & 11,051 & 21,422 & 11,477 & 22,054 & 11,423 & 22,153 \\
\hline 92 & 8,409 & 17,764 & 8,961 & 18,314 & 8,983 & 18,389 \\
\hline 93 & 6,271 & 14,318 & 6,668 & 14,928 & 6,655 & 14,954 \\
\hline 94 & 4,580 & 11,264 & 5,090 & 11,920 & 5,091 & 11,920 \\
\hline 95 & 3,201 & 8,507 & 3,620 & 9,235 & 3,606 & 9,357 \\
\hline 96 & 2,078 & 5,944 & 2,480 & 6,299 & 2,504 & 6,399 \\
\hline 97 & 1,295 & 3,949 & 1,465 & 3,881 & 1,455 & 3,851 \\
\hline 98 & 801 & 2,743 & 1,030 & 2,993 & 1,027 & 3,011 \\
\hline 99 & 499 & 1,947 & 632 & 2,008 & 653 & 2,052 \\
\hline 100 & 322 & 1,299 & $\mathrm{n} / \mathrm{a}$ & $\mathrm{n} / \mathrm{a}$ & 338 & 1,086 \\
\hline 101 & 194 & 830 & $\mathrm{n} / \mathrm{a}$ & $\mathrm{n} / \mathrm{a}$ & 176 & 697 \\
\hline 102 & 106 & 508 & $\mathrm{n} / \mathrm{a}$ & $\mathrm{n} / \mathrm{a}$ & 106 & 433 \\
\hline 103 & 54 & 286 & $\mathrm{n} / \mathrm{a}$ & $\mathrm{n} / \mathrm{a}$ & 62 & 244 \\
\hline 104 & 27 & 152 & $\mathrm{n} / \mathrm{a}$ & $\mathrm{n} / \mathrm{a}$ & 39 & 150 \\
\hline 105 & 12 & 82 & $\mathrm{n} / \mathrm{a}$ & $\mathrm{n} / \mathrm{a}$ & 28 & 95 \\
\hline 106 & 4 & 44 & $\mathrm{n} / \mathrm{a}$ & $\mathrm{n} / \mathrm{a}$ & 20 & 34 \\
\hline 107 & 2 & 21 & $\mathrm{n} / \mathrm{a}$ & $\mathrm{n} / \mathrm{a}$ & 0 & 16 \\
\hline 108 & 2 & 9 & $\mathrm{n} / \mathrm{a}$ & $\mathrm{n} / \mathrm{a}$ & 0 & 13 \\
\hline 109 & 2 & 4 & $\mathrm{n} / \mathrm{a}$ & $\mathrm{n} / \mathrm{a}$ & 0 & 4 \\
\hline $110+$ & 1 & 1 & $\mathrm{n} / \mathrm{a}$ & $\mathrm{n} / \mathrm{a}$ & 4 & 18 \\
\hline 90-99 & 52,184 & 112,991 & 56,058 & 117,690 & 56,073 & 118,243 \\
\hline $100+$ & 724 & 3,236 & 736 & 2,786 & 773 & 2,790 \\
\hline
\end{tabular}

Source: Authors' calculations; ABS

Note: 2016 Census counts are for 9th August 2016 while the new estimates and ERPs have a reference date of 30th June 2016 


\section{University Library}

\section{- M M N E R VA A gateway to Melbourne's research publications}

Minerva Access is the Institutional Repository of The University of Melbourne

Author/s:

Wilson, T;Temple, J

Title:

The rapid growth of Australia's advanced age population

Date:

2020-12

Citation:

Wilson, T. \& Temple, J. (2020). The rapid growth of Australia's advanced age population. Journal of Population Research, 37 (4), pp.377-389. https://doi.org/10.1007/ s12546-020-09249-7.

Persistent Link:

http://hdl.handle.net/11343/251815 